somewhat disappointing section as all the conditions included in it are scantily described.

The section on neoplastic diseases is good, and contains an excellent description of Ewing's tumours. With regard to the latter, Dr. Hertzler remarks that there are less than a dozen people in the world who understand this group of tumours, a point of view which might excite some controversy.

The bibliography at the end of each chapter contains a brief statement of what is discussed in the article referred to; this is a welcome innovation.

This book is well worth adding to one's surgical library.

\section{H. E. M.}

THE PRACTICAL TREATMENT OF DIABETES.-BY T. Izod Bennett, M.D. (Lond.), F.R.C.P. (Lond.). London: Constable and Company, Ltd., 1931. Pp. ix plus 107. Price, 6s. net. (Available from Oxford University Press, Bombay)

THE successful treatment of diabetes mellitus depends, to a large extent, on the intelligent co-operation of the patient and his family with the physician; to achieve this object an intelligent understanding of the character and nature of the malady is a great help to the patient himself. It is encouraging to find that workers on the problem of diabetes have realized this, and Dr. Bennett's book is a useful addition to that long series of books designedly written with this object in view. Not only educated patients, but junior practitioners as well, will be benefited by the practical descriptions of the modern treatment of diabetes given in this book.

There are a few points in the book which perhaps require reconsideration. For instance in figure 3 (page 22) the author gives a diagram representing the effect of the different meals during the day on the blood-sugar curve of a normal healthy individual; the small but steadily-continuous rise of blood-sugar extending for a period of three hours after taking breakfast and its slow fall during the next two hours, appear to us to be distinctly abnormal. Then, again, at lunch time (about 5 hours after breakfast), the blood-sugar in the chart is still shown to be much above the prebreakfast level, which again, in our opinion, indicates defect in the storage mechanism of the system. The same process is shown to occur-throughout the day and the only occasion when the blood-sugar is shown to come back to the pre-breakfast level is about midnight, i.e., 17 hours later! This chart appears to us to be somewhat misleading; we hope the author will revise it in the next edition.

In chapter II the author deals with the general principles in the treatment of diabetes, calculation of diet, etc. We note that a few minor inaccuracies have crept into the diet tables. For instance, in the second diet (page 40) the food value of four ounces of fried tomatoes has been shown as carbohydrate- $\mathbf{5}$ grammes, protein and fat- 0.5 gramme, whereas in the eighth diet (page 45) the same (this is put down there as 'potatoes', but the author has corrected it to read as 'tomatoes' in an erratum slip) is shown as having a value of carbohydrate -0 , protein -1 and fat -0 gramme. We take this to be an oversight, and hope to see it corrected in the next edition.

We are of opinion that the book gives very clear practical details about the treatment of diabetes which will help the young practitioner in giving necessary instructions to his diabetic patients, who should be able, also with the help of the book, to follow the instructions intelligently in making suitable selections of diet to meet their special requirements.

\section{J. P. B.}

NUTRITION AND DIET IN HEALTH AND DISEASE.-

By James S. McLester, M.D. Second Edition. Philadelphia and London: W. B. Saunders Company, Ltd., 1931. Pp. 891. Price, 36s. net

IT gives us genuine pleasure to have to review the second edition of Dr. McLester's book; the first edition we reviewed about 3 years ago. It may be considered to be one of the standard books on nutrition.

The science of nutrition is undoubtedly engaging increasing attention on the part of the general puolic, and is already occupying a large space, not only in the practice of medicine but also in surgery and midwifery. It is, therefore, gratifying to find that within the last few years much advance has been made in the development of this subject and the knowledge of its principles is now more widespread among general practitioners than at any time before.

As before, the author has ably dealt with the nutritional aspect of healon and disease in all its important bearings, physical, physiological, pathological, experimental and economic.

Many additions and changes have been made in some of the chapters, specially in the discussion of some of the metabolic diseases, such as diabetes, gout and obesity, in accordance with the modern ideas on the subject. Chapter XXI, dealing with the diseases of the blood, has been practically rewritten in view of the fact that much interesting work has been done recently on the classification of the nature of anæmias which necessarily affects the line of treatment. The recent work of Douglas and Tannenbaum on the mechanism of secondary anæmias has been incorporated in the book; this work shows that the measure of the bonemarrow activity depends on the reticulocyte count, because the appearance of reticulocytes in the circulating blood indicates that the erythropoietic system is active, also that the blood destruction can be measured -with a fair degree of accuracy (in the absence of liver disease) by the icteric index.

The section on vitamins has been considerably enlarged in view of recent discoveries, specially the work of Smith, Hendrick, and Goldberger on pellagra which has resulted in the identification of vitamin $G$ as an indispensable food factor, the lack of which from one's diet produces pellagra. Previously it was recognized that the vitamin B complex had mainly two indispensable principles-the antineuritic fraction as distinct from the heat-resisting P. P. (i.e., pellagra preventive) fraction. The latter fraction, according to the recent work of Goldberger, is now known to be identical with vitamin $\mathrm{G}$, which is contained in yeast, milk, tomatoes, bananas, eggs, meat, etc. The author however, does not seem to accept Goldberger's view unreservedly, and seems to be of opinion that, though vitamin-G deficiency may be a predisposing factor, the ultimate cause of pellagra is an infectious agent.

The section on the mineral requirement of the body has also been much enlarged. The question of availability of inorganic salts for nutritive purposes has been a subject of interesting controversy. The author has given us an able discussion with reference to the recent works of numerous investigators on the subject, which is most certainly worthy of perusal.

The section on the protein problem is a very interesting study. The author has discussed in some detail the practical side of the protein requirement of the body and after discussing the views of the two opposing schools of thought, viz, the German school headed by Viogt, advocating high protein diet, and the American school headed by Chittenden, advocating low protein diet, has come to the conclusion that 'to enjoy sustained vigour and to experience his normal expectancy, man must eat a liberal quantity (i.e., in excess of his " theoretic" needs, say 100 grammes daily) of good protein (i.e., protein of high biologic value, such as milk and meat)'. It may be mentioned here that investigations into the dietaries of some of the races in India conducted by McCay, McCarrison and others support the author's conclusions as to the importance of a liberal supply of good protein in the daily diet for the maintenance of health, strength and the resisting power against infection. The poor health of the people of some of the provinces in India, in our opinion, is due to chronic protein starvation.

A few new sections have been added, with considerable advantage to the reader, the most important 
amongst them being the toxæmias of pregnancy, protozoan infections of the bowels, etc.

The book gives a fairly exhaustive account of the scientific foundations on which our present knowledge of nutrition in health and disease has been built up. The addition of a bibliography at the end of almost every chapter is very welcome, because it serves as a guide to those who wish to amplify their knowledge on the subject. We have no hesitation in saying that the book is a valuable contribution to up-to-date knowledge on the subject and should prove to be a standard work of reference to those engaged in the problem of nutrition and diet, in health and disease.

J. P. B.

MEDICINE: ANALYTICAL REVIEWS OF GENERA MEDICINE, NEUROLOGY, PEDIATRICS. May Issue, 1931, Vol. $X$, No. 2. Baltimore, U. S. A.: The Williams and Wilkins Company. (English Agents are: Baillière, Tindall and Cox, London.) Price, 21s. per volume, and postage 2s. 6d. net. Single copy, 6s. 9d. net

$\mathrm{W}_{\mathrm{E}}$ have had the opportunity of reviewing many previous issues of 'Medicine'-the quarterly journal published by the Williams and Wilkins Co., Baltimore, and we have had nothing but praise for the useful and informative articles appearing therein. It is very gratifying to see that the present number (Vol. X, May 1931) has not departed from the standard set by others of the series. The chief article on nephrosis is an admirable compilation from the Department of Medicine. University of Chicago, and will fully repay careful study. The term 'nephrosis' came into the field comparatively recently (1905), and from that time onwards there has been a diversity of opinion about its significance. So many different theories have been put forward from time to time by eminent clinicians and pathologists in various countries regarding its causation that it is very difficult for the ordinary medical man to form a clear image of the disease. In this article a comprehensive review of all available literature has been made and sufficient evidence has been produced in favour of the existence of the disease, as a definite clinical and pathological entity, in contra-distinction to the nephrotic syndrome in chronic glomerular nephritis.

The second article, on "the influence of local factors for electivity in central nervous system disease processes', is the address of Professor Walther Spielmeyer of Germany before the Boston Society of Psychiatry and Neurology. This seems to be too abstruse for the general reader, but will give plenty of food for serious thinking to those interested in neurology.

R. N. C.

THE PHYSICAL AND RADIOLOGICAL EXAMINATION OF THE LUNGS.-By James Crocket, M.D., D.P.H., F.R.C.P.E. Second Edition. London: H. K. Lewis \& Co., Ltd., 1931. Pp. $x$ plus 296, with 151 illustrations, including 40 plates. Price, 16s. net

$I_{T}$ is a great pity that the title of this book is misleading and that the book is not as comprehensive as the title suggests. The material that is in its pages is, however, excellent and brings out many points not usually noted in the examination of chests. The titlepage modifies the title a little by adding "with special reference to tuberculosis and silicosis, including a chapter on laryngeal tuberculosis', but for any student to read through the book and find the pneumonias dismissed in about 16 lines and then only in a comparison with phthisis is disappointing. In the same way, bronchitis, pleural effusions, and new growths have hardly been mentioned. The methods and principles of the examination of a patient are so well gone into that it would probably mean only two or three more short chapters and a few accompanying radiograms to remedy the matter, and to make the book a textbook suitable for any student or practitioner renewing his acquaintance with medicine with special regard to chest complaints. As it is, tuberculosis and silicosis have been gone into very fully and other pathological conditions have scarcely been mentioned.

To any practitioner specialising, or contemplating specialising, in tuberculosis the book is ideal-we have here in one book the anatomy, physiology, and applied physiology of the chest, together with full clinical and radiological methods of examination and technique. The radiological section is particularly useful to the clinician who has to interpret his own films, and the reproductions of radiograms are good and well repay careful study.

A little point, but one which if attended to would make for increased pleasure in reading, is that where references to 'figures' have been made the page number has been omitted. This is especially noticeable in the anatomy section. It is not conducive to thorough or pleasant study to have to hunt laboriously through page after page of the book to find the required diagram which may be, and in several cases is, 100 pages further on in the text.

The glossary at the end of the book of terms used in connection with the lungs is an excellent idea and one that might well be copied by authors of other textbooks.

J. F. C.

ELEMENTS OF EMBRYOLOGY.-By Dr. Hyderali

Khan, F.R.C.S.E. Allahabad: The Indian Press, Ltd., 1931. Illustrated. Pp. 104. Price, Rs. 5

THIs small book on embryology deals with the developmental history in a concise manner, stating the accepted up-to-date views in a plain and simple style. It begins with the animal cell, fertilisation and segmentation, and then deals with the development of the systems one after another. At the end there is a description of the embryos and fœtuses at different periods of development. The book is meant not for those who intend to make a special study of the subject-for these reference to more elaborate textbooks is necessary -but for the students who require an elementary knowledge of the subject; for these the book is extremely suitable. It is also suitable for quick revision of the subject, as all the important facts have been incorporated in it in a concise manner. The book contains many illustrations some of which are in colours. There are some typographical errors which are expected to be rectified in the next edition.

\section{N. P.}

LASCAR HINDUSTANI FOR SHIP-SURGEONS.-By S. Chalmers Parry, M.A. (Cantab.), M.R.C.S., L.R.C.P. Second Edition. London: W. J. Clark and Co., Printers, Hanway Street, W.1. 1931. Pp. 48. Price.-Paper covers, 2s. 6d. net; Cloth bound, 3s. 6d. net

ANY European medical man practising in India will find this little book very helpful. It is written primarily for the ship's surgeon, but the essentially nautical terms are easily outnumbered by the essentially medical terms. To the tea-garden doctor it will be more useful than the ordinary "Aid to Conversation in Hindustani" which is to be found on the railway station bookseller's stall. Sentences such as 'I want four coolies to take my baggage to the hotel' may be very useful to the tourist, but the doctor will find the more prosaic 'Arj kitna tutti hooa hi?' much more practical.

\section{SPA TREATMENT.-Compiled and published by The} Harrogate Medical Society

The Harrogate Medical Society have issued a very useful booklet under the name of "Spa Treatment" Actually the subject is only dealt with from the point of view of the Harrogate doctor. Nevertheless it contains much useful information of general application. The book is meant for the doctor and not for the patient. A list is given of the various diseases and conditions which are likely to be benefited by spa treatment, and we are relieved to see that considerable 